\title{
Maternal and neonatal separation and mortality associated with concurrent admissions to intensive care units
}

\author{
Joel G. Ray MD MSc, Marcelo L. Urquia MSc PhD, Howard Berger MD, Marian J. Vermeulen BScN MHSc
}

Competing interests: None declared.

This article has been peer reviewed.

Correspondence to: Joel G. Ray, rayj@smh.ca

CMAJ 2012. DOI:10.1503 /cmaj.121283

\begin{abstract}
Background: Concurrent admission of a mother and her newborn to separate intensive care units (herein referred to as Co-ICU admission), possibly in different centres, can magnify family discord and stress. We examined the prevalence and predictors of mother-infant separation and mortality associated with coICU admissions.
\end{abstract}

Methods: We completed a population-based study of all 1023978 singleton live births in Ontario between Apr. 1, 2002, and Mar. 31, 2010. We included data for maternal-infant pairs that had co-ICU admission $(n=1216)$, maternal ICU admission only $(n=897)$, neonatal ICU (NICU) admission only ( $n=123236)$ or no ICU admission ( $n=898629$ ). The primary outcome measure was mother-infant separation because of interfacility transfer.

Results: The prevalence of co-ICU admissions was 1.2 per 1000 live births and was higher than maternal ICU admissions (0.9 per 1000). Maternal-newborn separation due to interfacility transfer was 30.8 (95\% confidence interval $[\mathrm{Cl}$ 26.9-35.3) times more common in the co-ICU group than in the no-ICU group and exceeded the prevalence in the maternal ICU group and NICU group. Short-term infant mortality $(<28$ days after birth) was higher in the co-ICU group (18.1 per 1000 live births; maternal ageadjusted hazard ratio [HR] $27.8,95 \% \mathrm{Cl} 18.2-$ 42.6) than in the NICU group (7.6 per 1000; ageadjusted HR 11.5, 95\% Cl 10.4-12.7), relative to 0.7 per 1000 in the no-ICU group. Short-term maternal mortality ( $<42$ days after delivery) was also higher in the co-ICU group (15.6 per 1000; age-adjusted HR $328.7,95 \% \mathrm{Cl} 191.2-565.2)$ than in the maternal ICU group (6.7 per 1000; age-adjusted HR 140.0, 95\% Cl 59.5-329.2) or the NICU group (0.2 per 1000; age-adjusted HR $4.6,95 \% \mathrm{Cl} 2.8-7.4)$.

Interpretation: Mother-infant pairs in the coICU group had the highest prevalence of separation due to interfacility transfer and the highest mortality compared with those in the maternal ICU and NICU groups.
A dmission of a newborn to a neonatal intensive care unit (NICU) produces a great deal of stress for the parents. ${ }^{1}$ A new mother who also falls ill may be unable to care for, or bond with, her newborn during the time of her illness. ${ }^{2}$ Although the father will experience a sense of loss of control when his infant is admitted to the NICU, ${ }^{3,4}$ this feeling is conceivably worsened when the mother too requires intensive care. In this situation of concurrent ICU admission (herein referred to as "co-ICU"), the mother and newborn may be in different areas of the same hospital or in different facilities. This separation would magnify the degree of mother-infant and family discord and stress and could create competing priorities for family members in terms of decision-making and support. Moreover, the situation would be made more devastating if the mother or newborn died in hospital and the other remained critically ill, or after discharge of one, the other required continuing hospital care or died.

Because of the serious, potentially negative consequences of co-ICU admissions, we examined the prevalence and predictors of motherinfant separation and mortality associated with co-ICU admissions.

\section{Methods}

\section{Study population}

We completed a retrospective population-based study. We included all singleton live births in the province of Ontario between Apr. 1, 2002, and Mar. 31, 2010. We excluded mother-infant pairs if the infant was born before 23 weeks' gestation or had a birth weight of less than $500 \mathrm{~g}$, or if the mother was not 14-50 years old or lived outside of the province.

\section{Data sources}

We used existing linked databases for the province of Ontario, all housed at the Institute for Clinical Evaluative Sciences (ICES; www.ices .on.ca). Individual obstetric deliveries were iden- 
tified in the Canadian Institute for Health Information's Discharge Abstract Database based on ICD-10-CA codes (International Statistical Classification of Diseases and Related Health Problems, Tenth Revision, Canada) (https://secure .cihi.ca/estore/productSeries.htm?pc=PCC189), and patient service and case-mix groups. The MOMBABY Database at ICES includes all inpatient admission records from the Discharge Abstract Database for mothers and their newborns delivered from fiscal year 2002/03 onward and links mothers and their newborns deterministically based on the maternal/newborn chart number. Each record in the MOMBABY Database contains the unique encrypted health care number, age and sex of the participant, the date of admission and up to 25 diagnoses identified with ICD-10-CA codes. We used the Discharge Abstract Database dataset to define study covariates, as well as maternal hospital admissions in the year before the index delivery date (Appendix 1, available at www.cmaj.ca/lookup/suppl /doi:10.1503/cmaj.121283/-/DC1).

We measured the proportion of women who were admitted to various ICUs during the study period using the special-care-unit codes contained in the Discharge Abstract Database (Appendix 1). These codes are standardized, and their use has been mandatory for reporting by all Ontario hospitals as of Apr. 1, 2002; they have a sensitivity of $96 \%$ and a specificity of $90 \%$ for adult ICU admissions. ${ }^{5}$ For neonatal morbidity, similar codes to those in the Discharge Abstract Database were previously validated in an Australian study involving infants born between 1994 and 1996 in New South Wales. ${ }^{6}$ For infant death, major disease diagnoses and the receipt of mechanical ventilation during the index hospital admission, the specificity was greater than $97 \%$ for each and the sensitivity typically above $80 \%{ }^{6}$ In Ontario, which has a universal health care system, and in an era of more accurate ICD-10 coding (since 2002/03), we would expect these performance measures to be higher.

Income quintile and location of residence (rural v. non-rural) were defined according to postal code using Statistics Canada census data.

\section{Exposure and outcome variables}

We evaluated 4 possible states arising during the index hospital admission: co-ICU, in which both the mother and newborn were admitted to ICUs; maternal ICU, in which only the mother was admitted to an ICU; NICU, in which only the newborn was admitted to a neonatal ICU; and no ICU, in which neither the mother nor the newborn were admitted to an ICU (reference category). Prevalence and 95\% confidence intervals
(CIs) for each ICU state at the time of the index hospital admission were calculated annually and for the overall study period.

The primary outcome measure was motherinfant separation due to interfacility transfer (transfer of one or the other from the delivery hospital to another facility or transfer of both from the delivery hospital to different facilities). We measured the occurrence of mother-infant separation in relation to each of the 3 ICU states (co-ICU, maternal ICU and NICU).

The secondary outcome measures were the prevalence and predictors of each ICU state, and the infant and maternal morbidity and mortality in the 4 categories. Maternal, obstetric and perinatal characteristics and morbid conditions associated with each ICU state were evaluated relative to the no-ICU group. All evaluated variables were chosen a priori.

Maternal and infant mortality after the index hospital admission were measured in the short term (up to 42 days after delivery for maternal mortality and up to 28 days after birth for infant mortality) and at 1 year.

The above analyses were repeated but were restricted to nulliparous women.

\section{Statistical analysis}

We evaluated the annual change in the prevalence of the co-ICU, maternal ICU and NICU states using a Cochran-Armitage test for trend. We compared measures of interfacility transfer across the ICU groups using a $\chi^{2}$ test. We used logistic regression analysis to identify maternal, obstetric and perinatal characteristics associated with each ICU state relative to the no-ICU group; the results are expressed as odds ratios (ORs) and 95\% CIs and are adjusted for maternal age.

For infant and maternal mortality, we used Cox proportional hazards regression to derive age-adjusted rates and hazard ratios (HRs) and 95\% CIs for short-term and 1-year mortality in each of the ICU states, with the no-ICU group as the reference category.

\section{Results}

\section{Characteristics of mother-infant pairs}

The initial study sample comprised 1065012 deliveries. We excluded deliveries if the mother had an invalid linkage number $(n=2015)$, was not a resident of Ontario $(n=1136)$, was less than 14 or more than 50 years old $(n=134)$, had a multi-fetal pregnancy $(n=36521)$, had a stillbirth $(n=357)$, had a delivery before 23 weeks' gestation $(n=690)$ or had a newborn whose birth weight was less than $500 \mathrm{~g}(n=181)$. The final sample comprised 1023978 singleton live births. 
Compared with mothers in the no-ICU group, those in the co-ICU group were slightly older and were more likely to be nulliparous, to have a lower economic status, to have a diagnosis of drug dependence, diabetes mellitus or chronic hypertension, and to have been admitted to hospital in the year before the index hospital admission (Table 1). Infants in the co-ICU group were delivered a mean of 3.8 (95\% CI 3.7-3.9) weeks earlier than those in the no-ICU group. Infants born at term constituted $45.9 \%$ of newborns in the co-ICU group, $82.6 \%$ of those in the maternal ICU group, $71.2 \%$ of those in the NICU group and $96.9 \%$ of infants in the noICU group. The highest rates of invasive mechanical ventilation were in the co-ICU group (18.0\% of mothers and $27.5 \%$ of infants) (Table 1).

The mothers' mean length of stay was 2.7 days longer in the co-ICU group than in the maternal ICU group. For newborns, the mean length of stay was 7.6 days longer in the co-ICU group than in the NICU group (Table 1).

\section{Prevalence of ICU admissions}

Overall, 124452 newborns (121.5 per 1000) and 2113 mothers (2.1 per 1000 live births) were admitted to an ICU during the study period. Most $(88.8 \%)$ of these mothers were admitted to a mixed medical-surgical or a medical ICU (Appendix 2, available at www.cmaj.ca/lookup /suppl/doi:10.1503/cmaj.121283/-/DC1). More than half of the 2113 mothers admitted to an ICU (57.5\% [1216]) had an infant who was admitted to a NICU. Of the 124452 infants admitted to a NICU, $1 \%$ (1216) had a mother who was admitted to an ICU (Table 1).

The prevalence of co-ICU admissions per 1000 live births was 1.2 (95\% CI 1.1-1.3) and was higher among nulliparous women $(n=649$;

Table 1: Characteristics of 1023978 women who delivered singleton liveborn infants in Ontario between 2002 and 2010, by intensive care unit (ICU) state*

ICU state; ${ }^{*}$ no. (\%) of woment

\begin{tabular}{|c|c|c|c|c|}
\hline \multirow[b]{2}{*}{ Characteristict } & \multicolumn{4}{|c|}{ ICU state; ${ }^{*}$ no. (\%) of woment } \\
\hline & $\begin{array}{l}\text { Co-ICU } \\
n=1216\end{array}$ & $\begin{array}{c}\text { Maternal ICU } \\
\quad n=897\end{array}$ & $\begin{array}{c}\mathrm{NICU} \\
n=123236\end{array}$ & $\begin{array}{c}\text { No ICU } \\
n=898629\end{array}$ \\
\hline Age, yr, mean $\pm S D$ & $31.2 \pm 6.2$ & $30.9 \pm 5.9$ & $29.8 \pm 5.8$ & $29.8 \pm 5.5$ \\
\hline Nulliparous & $649(53.4)$ & $524(58.4)$ & $65445(53.1)$ & $397317(44.2)$ \\
\hline \multicolumn{5}{|l|}{ Income quintile } \\
\hline 1 (lowest) & $348(28.6)$ & $215(24.0)$ & 32769 (26.6) & $197232(21.9)$ \\
\hline 2 & $270(22.2)$ & $206(23.0)$ & $26135(21.2)$ & $178178(19.8)$ \\
\hline 3 & $235(19.3)$ & $168(18.7)$ & $25060(20.3)$ & $181812(20.2)$ \\
\hline 4 & $224(18.4)$ & $178(19.8)$ & $22367(18.1)$ & $185535(20.6)$ \\
\hline 5 (highest) & $136(11.2)$ & $125(13.9)$ & $16564(13.4)$ & $151877(16.9)$ \\
\hline Urban residence & $1120(92.1)$ & $774(86.3)$ & $114140(92.6)$ & $801946(89.2)$ \\
\hline Tobacco or other drug dependence & $12(1.0)$ & $\leq 5$ & $1070 \quad(0.9)$ & $1328(0.1)$ \\
\hline Diabetes mellitus & 47 (3.9) & $20 \quad(2.2)$ & 4872 (4.0) & $13643(1.5)$ \\
\hline Chronic hypertension & $\leq 5$ & $\leq 5$ & $81 \quad(0.1)$ & $275(0.03)$ \\
\hline $\begin{array}{l}\text { Hospital admission in the year before } \\
\text { the index admission }\end{array}$ & $319(26.2)$ & $136(15.2)$ & $17733(14.4)$ & 67017 (7.5) \\
\hline $\begin{array}{l}\text { Gestational age at delivery, wk, } \\
\text { mean } \pm \text { SD }\end{array}$ & $35.4 \pm 4.0$ & $38.1 \pm 2.6$ & $37.4 \pm 3.2$ & $39.2 \pm 1.4$ \\
\hline Term delivery (gestation $\geq 37 \mathrm{wk}$ ) & $558(45.9)$ & $741(82.6)$ & $87798(71.2)$ & $871155(96.9)$ \\
\hline \multicolumn{5}{|l|}{ Invasive ventilation of any duration } \\
\hline Mother & $219(18.0)$ & $129(14.4)$ & $31(0.03)$ & $27(<0.01)$ \\
\hline Newborn & $335(27.5)$ & $75(8.4)$ & $19119(15.5)$ & 9518 (1.1) \\
\hline \multicolumn{5}{|l|}{ Length of hospital stay, d, mean \pm SD } \\
\hline Mother & $9.9 \pm 13.8$ & $7.2 \pm 10.8$ & $3.7 \pm 4.1$ & $2.3 \pm 1.6$ \\
\hline Newborn & $14.4 \pm 20.2$ & $5.8 \pm 6.1$ & $6.8 \pm 12.1$ & $2.0 \pm 1.4$ \\
\hline
\end{tabular}


1.4 per 1000 [95\% CI $1.3-1.5]$ ]) than among parous women $(n=567 ; 1.0$ per 1000 [95\% CI 0.9-1.1]). The prevalence of co-ICU admissions was higher than that of maternal ICU admissions (0.9 per 1000). Neither of these rates changed significantly over time, whereas the rate of NICU admissions declined significantly during the study period (Figure 1).

\section{Maternal-newborn separation due to interfacility transfer}

Interfacility transfer of a newborn was 37.1 (95\% CI 31.9-43.0) times more common in the coICU group than in the no-ICU group (Table 2). Separation of mother and infant due to interfacility transfer of one or the other, or of both to different facilities, was 30.8 (95\% CI 26.9-35.3) times more common in the co-ICU group than in the no-ICU group and exceeded the prevalence in the maternal ICU and NICU groups (Table 2). These rates were similar for nulliparous and parous women (data not shown).

\section{Morbidity}

Relative to the no-ICU group, substantial differences were observed in the likelihood of maternal and neonatal ICU admissions in association with maternal characteristics and comorbidities (Appendix 3A, available at www.cmaj.ca/lookup /suppl/doi:10.1503/cmaj.121283/-/DC1). These associated risk factors were often most pronounced in the co-ICU group and included maternal renal disease and preeclampsia; nearly one-third of the women in the co-ICU group had preeclampsia, as compared with less than $1 \%$ of women in the no-ICU group (Appendix 3A).

Several obstetric risk factors were significantly associated with co-ICU or maternal ICU admission (Appendix 3B). Only maternal hemorrhage and forceps delivery were significantly more common in the maternal ICU group than in the co-ICU group. The rate of cesarean delivery linearly increased by ICU status and was most common in the co-ICU group (78.6\%).

Of the perinatal factors, several were most pronounced in the co-ICU group, often even more so than in the NICU group (Appendix 3C). These factors included structural anomalies, preterm birth, low birth weight, birth asphyxia and diseases of prematurity.

The maternal, obstetric and perinatal OR estimates did not change significantly when we included only nulliparous women in the analyses (data not shown).

\section{Mortality}

Short-term infant mortality ( $<28$ days after birth) was higher in the co-ICU group (18.1 per 1000 life births; maternal age-adjusted HR 27.8, 95\% CI 18.2-42.6) than in the NICU group (7.6 per 1000; age-adjusted HR 11.5, 95\% CI 10.4-12.7), relative to the no-ICU group (0.7 per 1000) (Table 3; and Appendix 4A, available at www .cmaj.ca/lookup/suppl/doi:10.1503/cmaj.121283 /-/DC1). Co-ICU admission continued to be strongly associated with infant death up to 1 year after birth (age-adjusted HR 19.4, 95\% CI 13.328.2) relative to no ICU admission (Appendix 4B). These findings did not change significantly when we included only nulliparous women (data not shown).

Short-term maternal mortality $(<42$ days after delivery) was also higher in the co-ICU group (15.6 per 1000; age-adjusted HR 328.7, 95\% CI 191.2-565.2) than in the maternal ICU group (6.7 per 1000; age-adjusted HR 140.0, 95\% CI 59.5-329.2) or the NICU group (0.2 per

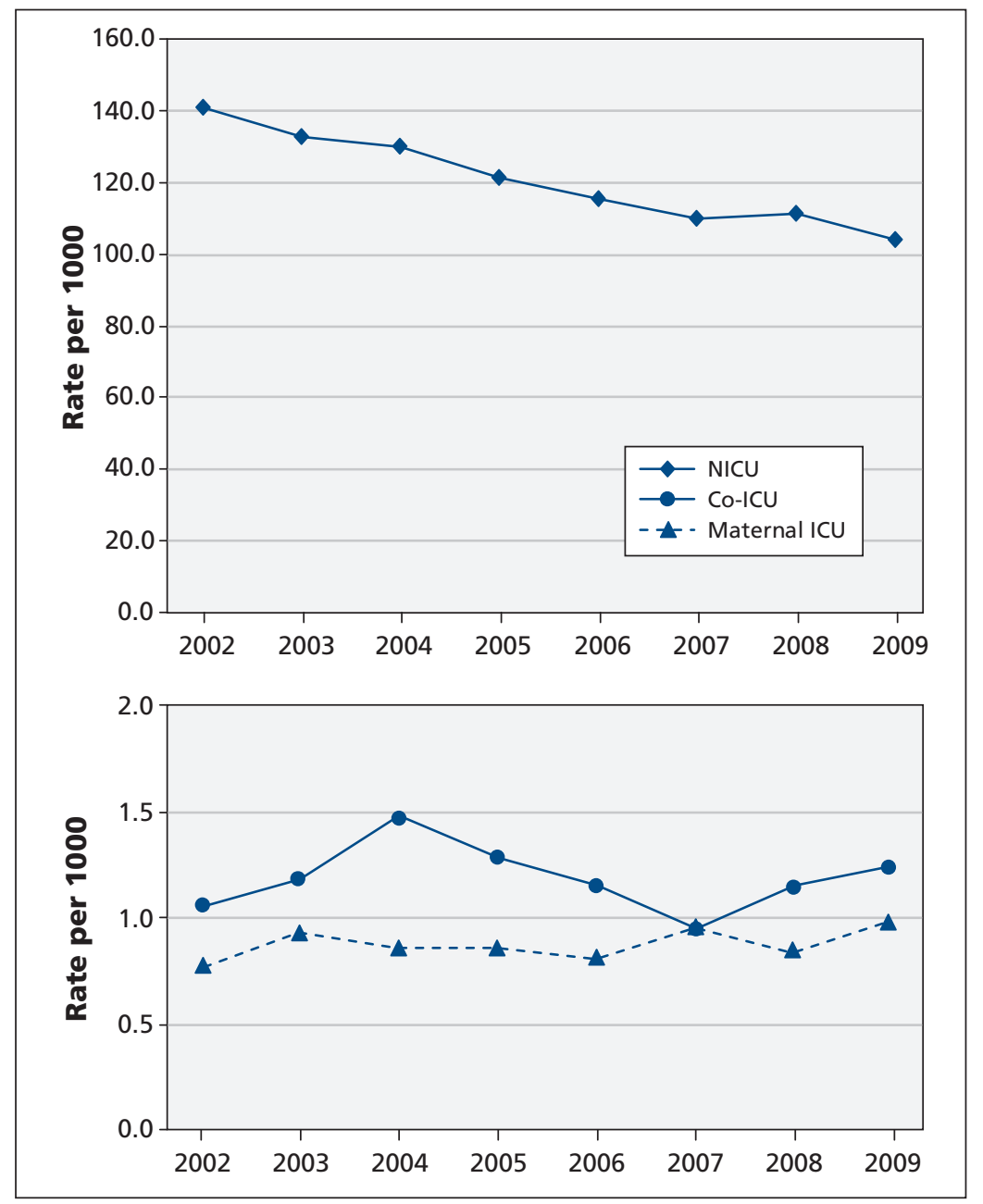

Figure 1: Annual prevalence (per 1000 live births) of admissions to intensive care units (ICUs) among 1023978 singleton live births in Ontario from 2002 to 2009. The top panel shows rates of admissions of infant only to neonatal ICU (NICU) ( $p$ for trend $<0.001$ ). The bottom panel shows rates of admissions of mother only (maternal ICU) ( $p$ for trend $=0.25$ ) and of concurrent admissions of mother and infant (co-ICU) ( $p$ for trend $=0.64$ ). The Cochran-Armitage trend test was used to test for trend over time. 
1000; age-adjusted HR 4.6, 95\% CI 2.8-7.4) (Table 3, Appendix 4C). At 1 year, maternal mortality remained significantly higher in the coICU group (Appendix 4D). Nulliparous women in the co-ICU group had a slightly higher rate of death at 42 days (1.7 per 1000) than parous women had (1.4 per 1000).

Nine of the mother-infant pairs died in the short term (0.01 per 1000) and 15 pairs died at 1 year $(0.01$ per 1000$)$ (Table 3$)$. The majority of these deaths involved nulliparous women.

\section{Interpretation}

In our study population, concurrent admission of a mother to an adult ICU and her newborn to a NICU (co-ICU admission) occurred 1.2 times per 1000 live births and was more common than admission of only the mother. The co-ICU group had the highest prevalence of mother-infant separation due to interfacility transfer, the longest mean hospital stay and the highest mortality.

Admission of a mother to an ICU is a clear indicator of severe acute maternal morbidity, and the concurrent admission of her newborn to a NICU is an indicator of further increased risk. About $50 \%$ of women affected by severe acute maternal morbidity do not require ICU admission; however, this depends on the defining criteria for the condition and the ICU resources available. ${ }^{7}$ Among women with the condition, those admitted to an ICU have a higher case-fatality rate than those not admitted (3.4\% v. $1.1 \%) .{ }^{8}$ In a multicentre study involving 97095 women who delivered in 12 Latin American countries, maternal ICU admission had the highest combined sensitivity $(48.0 \%)$ and specificity $(98.9 \%)$ for predicting maternal death before hospital discharge. ${ }^{9}$

Table 2: Interfacility transfers and maternal-infant separations, by intensive care unit (ICU) state*

\begin{tabular}{|c|c|c|c|c|c|c|}
\hline Outcome & $\begin{array}{l}\text { Total no. }(\%) \\
n=1023978\end{array}$ & \multicolumn{4}{|c|}{ ICU state;* no. (\%) of deliveries } & $p$ valuet \\
\hline Infant transferred & $12390(1.2)$ & $159(13.1)$ & $36(4.0)$ & $9026(7.3)$ & $3169(0.4)$ & $<0.001$ \\
\hline Mother transferred & $1586(0.2)$ & $26(2.1)$ & $36(4.0)$ & $263(0.2)$ & $1261(0.1)$ & $<0.001$ \\
\hline $\begin{array}{l}\text { Mother and infant transferred to same } \\
\text { or different facility }\end{array}$ & $1461(0.1) \S$ & $16(1.3)$ & $9(1.0)$ & $343(0.3)$ & $1093(0.1)$ & $<0.001$ \\
\hline
\end{tabular}

${ }^{*} \mathrm{Co}-\mathrm{ICU}=$ both mother and newborn admitted to ICUs during index hospital admission; maternal ICU = only mother admitted to ICU; NICU = only newborn admitted to ICU; no ICU = neither mother nor newborn admitted to an ICU.

$+\chi^{2}$ test, for comparison between the 4 ICU states.

¥Separation due to transfer of one or the other from the delivery hospital to another facility or transfer of both from the delivery hospital to different facilities. §Of the transfers of mother-infant pairs, $78(5.3 \%)$ involved transfer of the mother and infant to different facilities.

Table 3: Mortality outcomes in the short term and at 1 year after delivery, by intensive care unit (ICU) state*

\begin{tabular}{|c|c|c|c|c|c|c|}
\hline \multirow[b]{2}{*}{ Mortality outcome } & \multirow{2}{*}{$\begin{array}{c}\text { Total no. (rate per } \\
1000 \text { live births) } \\
n=1023978\end{array}$} & \multicolumn{4}{|c|}{ ICU state; ${ }^{*}$ no. (rate per 1000 live births) } & \multirow[b]{2}{*}{$p$ value $\dagger$} \\
\hline & & $\begin{array}{c}\text { Co-ICU } \\
n=1216\end{array}$ & $\begin{array}{c}\text { Maternal ICU } \\
n=897\end{array}$ & $\begin{array}{c}\text { NICU } \\
n=123236\end{array}$ & $\begin{array}{c}\text { No ICU } \\
n=898629\end{array}$ & \\
\hline \multicolumn{7}{|l|}{ Short term } \\
\hline Infant, $<28 \mathrm{~d}$ after delivery & $1568(1.5)$ & $22(18.1)$ & $8(8.9)$ & 939 (7.6) & $599(0.7)$ & $<0.001$ \\
\hline Mother, $<42 \mathrm{~d}$ after delivery & $95(0.1)$ & $19(15.6)$ & $6(6.7)$ & $27(0.2)$ & $43(0.05)$ & $<0.001$ \\
\hline \multicolumn{7}{|l|}{1 year after delivery } \\
\hline Infant & $2614(2.6)$ & $28(23.0)$ & $9(10.0)$ & $1451(11.8)$ & $1126(1.3)$ & $<0.001$ \\
\hline Mother & $262(0.3)$ & $23(18.9)$ & $9(10.0)$ & $68(0.6)$ & $162(0.2)$ & $<0.001$ \\
\hline Mother-infant pair & 15 (0.01)ף & $-\S$ & $-\S$ & $-\S$ & $-\S$ & \\
\hline
\end{tabular}


In the same study, NICU admission (OR 2.11, 95\% CI 1.95-2.28) and early neonatal death (OR $4.77,95 \%$ CI 3.74-6.07) were each associated with severe acute maternal morbidity. ${ }^{9}$ Our data on maternal and neonatal mortality (Appendix 3) are in keeping with these findings. Hence, coICU admission may be one optimal marker of maternal and infant morbidity and mortality, beyond maternal ICU or NICU admission alone.

Our rate of maternal ICU admissions (2.1 per 1000 live births) is similar to that in a national study from the Netherlands (2.4 per 1000 deliveries). ${ }^{8}$ In the Dutch study ${ }^{8}$ and in systematic reviews, ${ }^{7,10,11}$ obstetric hemorrhage and the hypertensive disorders of pregnancy together constituted $65 \%-80 \%$ of all ICU admissions; in our study, they constituted $65 \%$ of admissions in the maternal ICU group and $73 \%$ in the co-ICU group.

Although we observed 1 maternal ICU admission for every $100 \mathrm{NICU}$ admissions, there were 58 NICU admissions for every 100 maternal admissions. Future research comparing maternal and child bonding between these two situations and evaluating the impact on family, maternal well-being and infant development would be worthwhile.

It is conceivable that a newborn might be kept in hospital if his or her mother falls ill, and vice versa, but that should not require admission of the other to ICU. In fact, in the co-ICU group in our study, the infants' mean length of stay was 4.5 days longer than that of the mothers, whereas in the maternal ICU group, it was 1.4 days shorter. The length of hospital stay of the infant or mother might be prolonged when the other is admitted to an ICU, but that should normally reflect a stay in a newborn nursery or a regular ward.

What is the common pathological link between a mother and her newborn both being admitted to ICUs, and why does co-ICU admission reflect worse outcomes for both? Emphasis has typically been placed on the influence of maternal health on fetal health. ${ }^{12}$ However, abnormalities of the maternal and fetal placental circulations may often co-exist, ${ }^{13}$ and a diseased placenta may adversely affect mother and fetus alike. ${ }^{14}$ Placental dysfunction may result in preeclampsia, placental abruption and placental infarction, ${ }^{15}$ paralleled by an increased rate of preterm cesarean delivery and involvement of the maternal hepatic, cardiac, renal and cerebral systems. ${ }^{16-19}$ Adverse effects on the fetus may include poor growth, birth asphyxia, ${ }^{20}$ prematurity ${ }^{21}$ and death. ${ }^{22} \mathrm{~A}$ retrospective case-control study involving detailed placental examination following co-ICU, maternal ICU and NICU admission relative to no ICU admission would be one efficient way to evaluate whether differences exist in pla- cental pathology. Although preterm delivery of an ill mother certainly predisposes her newborn to the diseases of prematurity, about $45 \%$ of the deliveries in the co-ICU group in our study were at term. Thus, it is likely that newborn morbidity in the co-ICU group did not solely reflect preterm delivery of an ill mother.

In addition to being at high risk of death, newborns admitted to the NICU experience long-term morbidity. ${ }^{23}$ This produces a great deal of stress for the parents. ${ }^{1}$ With co-ICU admission, there is an increased chance that mother and child will be separated. Qualitative research is needed to better understand the impact of coICU admission on a mother, her partner and her family, both in the immediate postpartum period and in relation to subsequent bonding. ${ }^{2,3}$

Coordination and communication of care plans between the adult and neonatal ICUs could lessen the burden and frequency of separation of mother and newborn seen with co-ICU admissions. Regionalized obstetric programs could be equipped to take care of both a sick mother and a sick newborn. If interfacility transport is required, attempts could be made to transfer mother and baby to the same destination. The use of a NICU webcam could help a conscious mother in the ICU view her newborn remotely on a laptop or portable device. ${ }^{24}$ Discharge planning and post-hospital care may need to be coordinated to deal with a recovering mother and her newborn. Given that co-ICU admission was associated with the highest rates of maternal and infant death, bereavement counselling may need to be modified accordingly. Finally, because of the ongoing risk of death after discharge (6 of the 28 infant deaths and 4 of the 23 maternal deaths in our study occurred beyond the window of early death), evaluation of the well-being of mothers and their infants - in clinical and research terms - should continue after hospital discharge.

\section{Strengths and limitations}

We included data for all singleton live births in the province of Ontario, where maternal and newborn care is provided in a universal health care system and health care outcomes are reported by all hospitals using standardized ICD10-CA diagnostic coding methods. This enabled us to produce statistically precise and generalizable estimates of prevalence and risk.

Our study has limitations. First, because we included only singleton births, our findings may not be applicable to multi-fetal pregnancies, whose maternal and perinatal risk factors and outcomes can differ from those of singleton pregnancies. ${ }^{25}$ 
All of the maternal variables we found to be associated with maternal and neonatal ICU admission, except for hospital admission in the preceding year, were captured in the index hospital admission. Hence, the effects of pre-existing maternal comorbidities could not be distinguished from those arising at the time of, or soon after, ICU admission. However, for variables such as maternal hemorrhage, preeclampsia and cesarean delivery, it is highly likely that they occurred shortly before maternal ICU admission. ${ }^{10}$ The rate of cesarean delivery among women admitted to ICU has been reported to be about $65 \%,{ }^{7}$ which is nearly the same as the rate in the maternal ICU group in our study. In many instances, cesarean delivery is needed because of the clinical condition causing the morbidity. ${ }^{?}$

Details about maternal tobacco use were restricted to a diagnosis of tobacco dependence, which was combined with other drug dependence. Also, maternal body mass index was not captured in the administrative databases that we used. Such variables might also predict the risk of maternal and neonatal ICU admission.

\section{Conclusion}

Mother-infant pairs in the co-ICU group had the highest prevalence of separation due to interfacility transfer and the highest mortality compared with those in the maternity ICU and NICU groups.

\section{References}

1. Lefkowitz DS, Baxt C, Evans JR. Prevalence and correlates of posttraumatic stress and postpartum depression in parents of infants in the Neonatal Intensive Care Unit (N-ICU). J Clin Psychol Med Settings 2010;17:230-7.

2. Feldman R, Weller A, Leckman JF, et al. The nature of the mother's tie to her infant: maternal bonding under conditions of proximity, separation, and potential loss. J Child Psychol Psychiatry 1999;40:929-39.

3. Anisfeld E, Lipper E. Early contact, social support, and motherinfant bonding. Pediatrics 1983;72:79-83.

4. Arockiasamy V, Holsti L, Albersheim S. Fathers' experiences in the neonatal intensive care unit: a search for control. Pediatrics 2008;121:e215-22.

5. Scales DC, Guan J, Martin CM, et al. Administrative data accurately identified intensive care unit admissions in Ontario. J Clin Epidemiol 2006;59:802-7.

6. Ford JB, Roberts CL, Algert CS, et al.; NICUS group. Using hospital discharge data for determining neonatal morbidity and mortality: a validation study. BMC Health Serv Res 2007;7:188.

7. Baskett TF. Epidemiology of obstetric critical care. Best Pract Res Clin Obstet Gynaecol 2008;22:763-74.

8. Zwart JJ, Dupuis JR, Richters A, et al. Obstetric intensive care unit admission: a 2-year nationwide population-based cohort study. Intensive Care Med 2010;36:256-63.

9. Souza JP, Cecatti JG, Faundes A, et al. Maternal near miss and maternal death in the World Health Organization's 2005 global survey on maternal and perinatal health. Bull World Health Organ 2010;88:113-9.

10. Zeeman GG. Obstetric critical care: a blueprint for improved outcomes. Crit Care Med 2006;34:S208-14.

11. Pollock W, Rose L, Dennis CL. Pregnant and postpartum admissions to the intensive care unit: a systematic review. Intensive Care Med 2010;36:1465-74.
12. Shy KK, Brown ZA. Maternal and fetal well-being. West J Med 1984;141:807-15.

13. Redline RW. Placental pathology: a systematic approach with clinical correlations. Placenta 2008;29:S86-91.

14. Khankin EV, Royle C, Karumanchi SA. Placental vasculature in health and disease. Semin Thromb Hemost 2010;36:309-20.

15. Ray JG, Vermeulen MJ, Schull MJ, et al. Cardiovascular health after maternal placental syndromes (CHAMPS): populationbased retrospective cohort study. Lancet 2005;366:1797-803.

16. Lykke JA, Langhoff-Roos J, Lockwood CJ, et al. Mortality of mothers from cardiovascular and non-cardiovascular causes following pregnancy complications in first delivery. Paediatr Perinat Epidemiol 2010;24:323-30.

17. Martin JN Jr, Rinehart BK, May WL, et al. The spectrum of severe preeclampsia: comparative analysis by HELLP (hemolysis, elevated liver enzyme levels, and low platelet count) syndrome classification. Am J Obstet Gynecol 1999;180:1373-84.

18. Murphy DJ, Stirrat GM. Mortality and morbidity associated with early-onset preeclampsia. Hypertens Pregnancy 2000;19: 221-31

19. Belfort MA, Clark SL, Sibai B. Cerebral hemodynamics in preeclampsia: cerebral perfusion and the rationale for an alternative to magnesium sulfate. Obstet Gynecol Surv 2006;61:655-65.

20. Roberts DJ, Post MD. The placenta in pre-eclampsia and intrauterine growth restriction. J Clin Pathol 2008;61:1254-60.

21. Ananth CV, Vintzileos AM. Maternal-fetal conditions necessitating a medical intervention resulting in preterm birth. Am J Obstet Gynecol 2006;195:1557-63.

22. Stillbirth Collaborative Research Network Writing Group. Causes of death among stillbirths. JAMA 2011;306:2459-68.

23. Kirkby S, Greenspan JS, Kornhauser M, et al. Clinical outcomes and cost of the moderately preterm infant. Adv Neonatal Care 2007; 7:80-7.

24. Rhoads SJ, Green AL, Lewis SD, et al. Challenges of implementation of a web-camera system in the neonatal intensive care unit. Neonatal Netw 2012;31:223-8.

25. Mukhopadhaya N, Arulkumaran S. Reproductive outcomes after in-vitro fertilization. Curr Opin Obstet Gynecol 2007;19:113-9.

Affiliations: From the Departments of Medicine (Ray), and Obstetrics and Gynecology (Berger), St. Michael's Hospital, University of Toronto; the Keenan Research Centre Li Ka Shing Knowledge Institute (Ray, Urquia), St. Michael's Hospital; and the Institute for Clinical Evaluative Sciences (ICES), University of Toronto (Ray, Urquia, Vermeulen), Toronto, Ont.

Contributors: Joel Ray, Howard Berger and Marian Vermeulen were responsible for the study concept. Marcelo Urquia was involved with the study design. Joel Ray, Marcelo Urquia and Marian Vermeulen were involved with the analysis and interpretation of the data. All of the authors contributed to the drafting and critical revision of the manuscript. Marian Vermeulen had full access to all of the data in the study and takes responsibility for the integrity of the data and the accuracy of the data analysis. All of the authors approved the final version of the manuscript submitted for publication.

Funding: This study was funded by the Canadian Foundation for the Study of Infant Deaths. The foundation had no role in the study design, data collection or analysis, decision to publish or preparation of the manuscript. No honorarium, grant or other form of payment was received by the authors to produce this manuscript.

Acknowledgement: The authors thank Kinwah Fung, ICES, for help in identifying interfacility transfer codes and other codes used in the MOMBABY Database.

Disclaimer: This study used data from the Institute for Clinical Evaluative Sciences (ICES). The institute is funded by an annual grant from the Ontario Ministry of Health and LongTerm Care. The opinions, results and conclusions reported in this paper are those of the authors and are independent from these sources. No endorsement by ICES or the Ontario ministry is intended or should be inferred. 